\title{
Waste equals energy: decentralised anaerobic waste treatment and local reuse of return flows
}

\author{
A. van Timmeren \\ Delft University of Technology, Faculty of Architecture, Climate Design, \\ Delft, The Netherlands
}

\begin{abstract}
In the built environment, the distance created between the (environmental) problem and its solution leads to more and more complexity. The process of changing the interrelated public and private services, systems and infrastructures is becoming more and more complicated and less predictable. Together with the increased scaling, the convergence of utilities and the growing number of parties and techniques involved, the end users' (consumers') subjective dependence (heteronomy) has increased. This asks for a simplification of the processes, products (or rather, services). A larger concentration on integral provision of services, or, in other words, the supply and management of integral packages, offers possibilities. This seems to be reinforced by the ongoing liberalization processes. This paper will focus on an innovative concept of integrated decentralised technologies for wastewater and organic waste treatment with energy and nutrients recovery. The concept is called Sustainable Implant (SI). Principally, the concept is based on a small-scale biogas installation (with treatment of blackwater and organic waste), Combined Heat Power (CHP) and accompanying closed glasshouse with 'hanging gardens'. These 'hanging gardens' are situated in a non-ventilated space with heat (and water) recovery, heat/cold storage (in an underlying aquifer) and with injection of the surplus $\mathrm{CO}_{2}$ of the biogas plant. The SI will be realized as a part of this semi-public building and has an interconnecting role between both district and building, inhabitants and visitors. The system layout and the dimensioning backgrounds are explained in this paper. Additional emphasis is put on maintenance, conservation and administration of the integrated whole, and the possible consequences for the district and its inhabitants.
\end{abstract}

Keywords: anaerobic waste treatment, decentralisation, local reuse. 


\section{Introduction}

There is a common consensus in society about the necessity of fundamental facilities for meeting the most fundamental needs in the own living environment, viz. "Maintenance", one of the so-called primary necessities of life. The availability of energy and food, including clean drinking water, and the removal of waste (water) are parts of it. It is no use trying to introduce sustainability measures that harm this fundamental need. Many relevant participants however do not seem to realise that other, more sustainable alternatives can be found by abandoning the specific characteristics of the traditional paradigms rather than following them. The dominant participants have an interest in using existing structures as efficiently as possible and in developing them further with as few risky investments as possible. As yet, the cost of transport in most of these 'essential flows' (energy and sanitation, i.e. drinking water and waste water and waste) is not taken into account, and there is little product differentiation, while these aspects in particular offer possibilities for alternatives that support sustainable development [1].

Looked on from the aim of "sustainable development", the path of expansion selected (centralisation) is not necessarily the optimum as perceived subjectively. Building infrastructure almost always implies slow and large-scale processes in the "underground" layer. For a structural solution and preservation, the technical infrastructure should be considered at the lowest layer within a model of layers. It will be leading for the design and the allocation of the faster dynamics of the overlying layers: the layer of the overground "networks" and that of "occupation". However, there are clear differences between the characteristics of the various central networks, in the energy and sanitation sub flows each as well as between the energy and sanitation supply as a whole. They are caused by different "central scales" of application and different extents of visibility, but also by the management structure and the presence or absence of liberalization processes. The infrastructure strongly correlates with production (supply as well as drainage). A change desired in the infrastructure, e.g. a bottleneck with respect to capacity, can be solved by investing in extending the infrastructure (now often accepted), but often also by adapting the "production" or "treatment" in strategic spots of the (central) grid. This is the background for the presented research (Timmeren [1]). It is argued that for a lasting sustainable urban development and especially a necessary improved network geometry with respect to the essential 'flows', further development based on the future of scaling-up and heteronomy of different networks and users will have to be combined with decentralised sub networks aiming at autonomy.

The research was commissioned by the Delft University of Technology (TUD) in The Netherlands as part of the D.I.S.C. Research Programme (Design Integration of Sustainability \& Comfort) of the Climate Design \& Environment chair (CD\&E). In addition CORE International, Haskoning Nederland, Innogas and Thecogas Biogas B.V., are responsible for the presented Culemborg case related quantitative and qualitative process analysis (battery limits) and the economic implementation study. 


\section{Heteronomy and autonomy}

It has turned out that the ongoing processes of liberalization have put pressure on the importance of the certainty of supply, and also removal. Working certainty of supply and independence out in further detail seems necessary, or even essential, not only for further development based on the future of scaling-up and heteronomy of different networks and users ("economies of scale"), but also for decentralisation ("scale economy") [2]. A possibility is connecting or disconnecting (decentralised) sustainable sub production (generation or processing capacity). This may be realised by including sustainability, via reliability, as an added value at relatively little cost, e.g. in the form of a decentralised (autonomous) utility and backup. Too little advantage is taken of this aspect of sustainability. It may imply a gradual change of the paradigm, following a sliding time scale rather than a radical change at a certain, perhaps unexpected, point in time to come [3]. Moreover, it may involve short-term interventions for long-term guarantees (sustainability, guarantees for supply/processing and in the end affordability). Such a principle may be useful as a kind of fallback scenario for, for example, a serious and unforeseen dysfunction of the current process of further scaling up and liberalization of sectors.

There are clear differences between the characteristics of the various central networks, in the energy and sanitation sub flows each as well as between the energy and sanitation supply as a whole. They are caused by different "central scales" of application and different extents of visibility, but also by the management structure and the presence or absence of liberalization processes. For sectors that are left to market forces, positive effects are to be expected on the efficient use of the infrastructures by oligopolistic market types, and, thus, on the affordability of the accompanying services. However, market participants have no interest in overcapacity, which puts pressure on the reliability of supply (by a maximum bid on the available capacity). Pressure can also be put on the other long-term interests, including maintenance of grids and investments in, research into or application of innovations, e.g. those that aim at sustainable development. At the same time, main aspects for users are sustainability, a guarantee on supply and processing and affordability. Where the essential infrastructures are concerned, the liberalization of the markets shows that the goals set concerning sustainability cannot always be accomplished in an integral way. At a national level, there is too little grip on the developments. The demand for supervision or rules at a supra-national level is being heard, and this causes one of the reasons for liberalization to be surpassed.

The "dialectics of progress" and the so-called "prisoner's dilemma" force themselves upon us: the deviation from this specific unsustainable (end-of-pipe) type of solution(s) is so expensive and will involve such far-reaching social consequences that there seems to be no other choice than continuing with these (expensive) infrastructures and systems. The distance created between the (environmental) problem and its solution leads to more and more complexity. The process of changing the interrelated public and private services, systems and 
infrastructures is becoming more and more complicated and less and less predictable [3]. Together with the increased scaling, the convergence of utilities and the growing number of parties and techniques involved have increased the end users' (consumers') subjective dependence (heteronomy). This asks for a simplification of the processes, products (or rather: services) and parties involved. In energy supply, there should be more emphasis on increasing the flexibility in the current (infra)structures, including Town and Country Planning in its entirety. The more so since it can be expected that there will not be only one decisive future technology to solve the coming problem(s) concerning security of supply and sustainable development. A larger concentration on integral provision of services, or, in other words, the supply and management of integral packages, offers possibilities. This seems to be reinforced by the ongoing liberalization processes. Another solution is having the level of application attune better to the lifestyle and direct surroundings of the users. Decentralised or local systems do respond to that demand. The basis of solutions is formed by urban planning that is based on 'interconnection', as well as waste management in general, and on closure of the essential cycles (energy, carbon, nutrients and water) inside urban developments, or as close to them as possible. The decentralisation and, in some cases, even complete disconnection of central (infra)structures are at the centre of the developing emancipation of systems of which they are a part.

Two development processes concerning decentralised technology for the purpose of autonomy have come forward as topical: viz. first, the efficiency and improvements in the integration of sub techniques and 'real-time' co-ordinated, connected concepts, and, second, a better harmony between supply (input) and demand of the (different) sub flows. Additionally, there are two more general underlying development processes. The first is the environment-technical, environmental and, to some degree, also social optimization of decentralised systems within (semi-) autonomous projects. The second underlying development process concerns the link to economic applications related to the surroundings, often determined by soil or users, including taking carbon and nutrients back to agriculture or so-called 'urban agriculture' concepts [4] and other lateral applications or possibilities. Especially in the field of small-scale Combined Heat Power generation and ecological sanitation systems important efforts have been made. The latter, so-called DESAR (Decentralised Sanitation and Reuse) systems, offer an alternative for the current status quo. The idea behind these kind of smaller systems is their relative simplicity, smaller investment risks and adaptability, and therefore their possibility to create extra (sustainable) capacities. There are still few examples of living and working environments with solely integrated systems concerning decentralised sanitation, energy and reuse (whole life urban sustainability concepts). However in several developed and developing countries more and more examples are realised or close to completion [5].

A decentralised system must not be characterized as a static system, since there is an ongoing change of an existing situation. Technical (de)centralisation concerns (a change of/in) systems, while the scale level of an administrative 
decentralised system is relatively fixed. It depends on the technique of the administrative body, the context and the position of the observer. In the case of administrative decentralisation, there is a distinction according to the nature of the administrative bodies: territorial decentralisation (between/ carried out by Government, Province and Municipality) and functional decentralisation (e.g. within the Municipality).

As for technical decentralisation, the various flows have different definitions of (the scale of) sub clusters and of "decentralised" sub networks and subsystems. Often, there is vagueness even within the various flows.

The present-day competitive advantage of "sunk costs" for conventional (centralised) solutions, to what decentralised alternatives will be compared, should be avoided. Strategic niche management can be of help here: Because of the relative new market of (technical) decentralisation, "niches" can be created. In doing this in a planned way, it is called "strategic niche management" [6]. The strategic approach should focus on the higher dynamic efficiency of the decentralised systems: changed circumstances are easier to be anticipated with the help of decentralised systems. Investment risks may decrease in this way, which is especially of more importance in liberalizing markets. The use of new, sustainable technology and sub flows leads to larger quantitative fluctuations in supply, the peak load as compared to the average consumption (especially of the energy flows) and to the introduction of various (parallel) qualities (particularly of the sanitation flows), or, in other words, to a differentiation of products and services within the various technical infrastructures.

Almost all decentralised sustainable energy sources have a low energy density, which, together with their variable character, will contribute to the obvious choice for a decentralised implementation. In the case of energy generation out of wastewater flows, this particularly holds for systems based on natural technologies. For decentralised energy generation as well as decentralised sanitation systems, this leads to more use of space. This disadvantage is the reason why decentralised systems should be integrated with other architectural and/or natural facilities and functions as much as possible.

Generally speaking, the two main problems in decentralised solutions are scepticism of the leading (often dominant) parties involved and the larger influence of a fluctuating flow size. The previous is particularly caused by responsibility (certainty) and liability. This scepticism will increase because of the necessary transition of the market(s) from supply of products to supply of services. The aspect of the flow size (in fact, the basis for the technical "economies of scale") can be met locally by modern techniques of planning and tuning, the so-called "Real Time Control", and the subdivision into parallel facilities. Thus, the remaining main points of interest for improving the competitiveness of decentralised systems and actually achieving the advantages for the environment and the users are the organization and implementation of maintenance, exploitation, provision of services and inspection of the various systems, together with the availability of backup provisions if necessary.

Two development processes concerning decentralised technology for the purpose of autonomy have come forward as topical: viz. first, the efficiency and 
improvements in the integration of sub techniques and co-ordinated, connected concepts, and, second, a better harmony between supply (input) and demand of the (different) sub flows. Additionally, there are two more general underlying development processes. The first is the environment-technical, environmental and, to some degree, also social optimization of decentralised systems within semi-autonomous projects. In spite of the potential of the underlying optimization principle of the "scale economy" claimed in much of the literature and projects, and in spite of its importance, which was also proven, it has only been applied to a small extent. Consequently, there still are not many "economies of scale" in this area. However, the sub aspects concerning the application freedom and environmental integration (smaller sizes, fewer secondary demands, etc.) and user-related demands (comfort, ease of use, costs, etc.) do improve noticeably. The second underlying development process concerns the link to economic applications related to the surroundings, often determined by soil or users, including taking nutrients back to agriculture and other lateral applications or possibilities, such as energy service companies.

\section{Case sustainable implant, 'Lanxmeer' district, Culemborg}

An important (partly realised) case study within the presented research in which interconnection of public utilities and local autonomy has been elaborated is the project 'EVA Lanxmeer'. It concerns an ecological settlement in the small-scale city of Culemborg, The Netherlands (www.eva-lanxmeer.nl).

The location of the EVA project is unique: This was the first time in The Netherlands that permission was given to build in the vicinity of, and partially within the protection zone of a drinking water extraction area. The regional government allowed building at this site only under the guarantee that it would carefully be built according to modern 'deep green' principles. The project has been carried out in different phases and will consist of approximately 250 houses and apartments, (collective) gardens and ecological office buildings. In addition to special functions such as a biological City farm, the EVA Centre (education, information and conference centre) is also situated in this district, along with a hotel and Sustainable Implant facilities. The natural cycles are paramount within the overall structure.

At first, the district's energy concept of the district had completely autarkic living as its main principle. Because of the concept of autarky and, consequently, the requirement for energy being available 'on demand', it was decided to use chemically bound energy, in the form of biogas. The production of gas from (organic) waste flows in the district has two positive effects at the same time: not only does gas become available, but also there will be no need for a connection to the public sewage system. For the production processes it is of importance that the percentage of solid substance in the fermenter is as high as possible: the energy content of black water is determined by the solid mass. Therefore, it is of importance to decrease the quantity of flushing water as much as possible. The municipality - in its role as project developer - chose the booster option to achieve this. Since green waste is also included in the process, the need for 
refuse collection has been reduced. The combination of black water and green waste offers advantages. Firstly, the amount of biomass available will be higher and therefore the gas proceeds will be larger; secondly, the 'fresh black water' implies a constant supply of fermenting biomass, which is good for the stability of the fermentation process.

The fermentation of waste is not the end of the process. Other integral parts of the process include improving the gas to a usable quality, purifying the effluent of the fermenter to a level that it can be discharged into the surface water without major problems, and processing the sludge without odour nuisance. Because of the $\mathrm{E}$ for Education in EVA, a Living Machine is taken as a starting point for purifying the effluent (Todd and Josephson [11]). With respect to the necessary exploitation of the system it has been decided to add two other decentralised concepts, viz. a facility for further separating various waste fractions ('Retourette' or 'Recycle Shop'), and the possibility for joint e-commerce supply ('E- Fulfilment'). The total system is called the "Sustainable Implant" or in short: SI [7]. The SI has been planned on the transition of the district into the surrounding (urban) areas, in the same lot as the EVA Centre and hotel. The technical installations will be integrated in an architectural solution, in such a manner that they will take up as little space as possible.

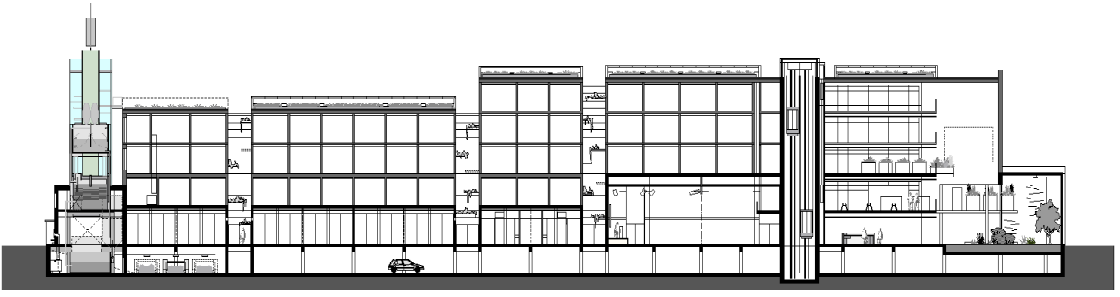

Figure 1: Section over the EVA Centre and hotel with sustainable implant (left).

The main component concerns the anaerobic treatment of waste and wastewater, producing biogas. The process of producing biogas (energy generation) and wastewater treatment can be divided into various sub processes:

Gathering black water on the one hand and green household waste (and to some extent garden waste) on the other, and leading them into the system;

- The fermentation process, with biogas, effluent and sludge as its output;

- Purifying and improving the gas into natural fossil gas equivalent;

- Purifying the effluent until it has surface water quality;

- Composting sludge into usable garden compost.

In addition a collection facility for waste and e-delivery, and a re-use step concerning the methane (biogas), water and carbon are added:

- Collection of separated waste flows (Retourette) and e-delivery goods of the district; 
- Using the biogas in a combined heat power plant (CHP), $\mathrm{CO}_{2}$ in glasshouses and purified water in the spa and vitality facilities of the hotel.

The biogas is a mixture of $65 \%$ methane, $34 \% \mathrm{CO}_{2}$ and some remaining gases (with a maximum of $1 \%$ ), e.g. sulphur hydrogen. In addition to the biogas, the digestion output of the fermentation process (approximately $5 \mathrm{~m}^{3} /$ day) consists of slurry, that is divided into a solid fraction (approximately $40 \%$ solids) and a fluid fraction by a screw press. The fluid fraction is free from pathogens. However, it is still polluted, so that extra purification is necessary before it can be discharged to surface waters [8]. This can be done by using helophytes filters. Since there will be a Living Machine as part of the EVA Centre, the effluent will be added to the input flow of the Living Machine (that will also process the black water from the EVA Centre and the hotel). There are two solutions for the solid fraction from the screw press: compost it in heaps in a well-closed compost room, or entering the slurry from the fermenter into the Living Machine. Because of uncertainties with respect to the process quality of this sub flow in the Living Machine, the first option was chosen. An advantage of using a compost room is that also the final maturation can take place there. After the maturation, the compost can be removed and brought back to the city-farm. The air in the compost room is extracted and purified by a bio-filter. There are two options for the biogas from the fermentation tank, the first being its transportation back (as natural fossil gas equivalent) to the homes, the second being burning it in a small Combined Heat Power installation. The latter option has been selected.
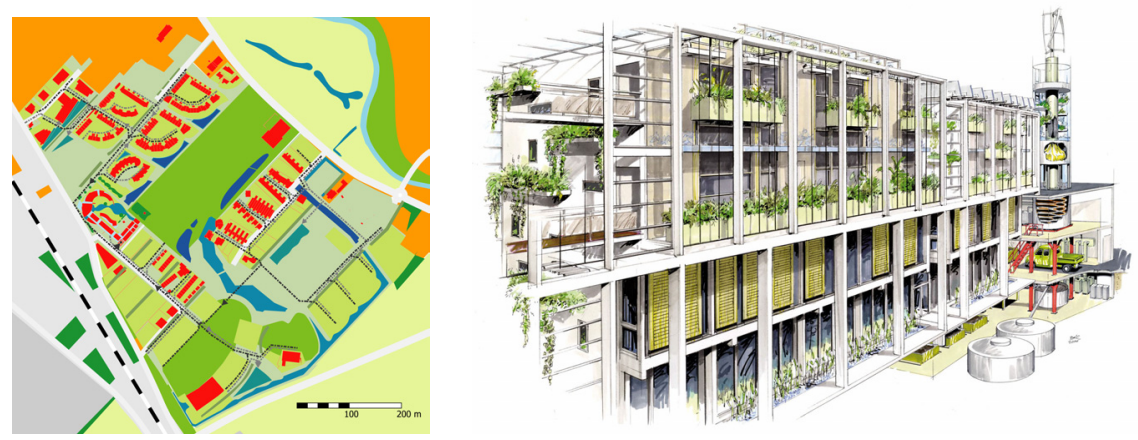

Figure 2: Plan of the Lanxmeer district (Culemborg, The Netherlands), and impression of the EVA Centre/hotel with sustainable implant (right).

A net amount of approximately 70 natural fossil gas equivalents remains and electrical energy surplus of $81 \mathrm{kWh} / \mathrm{d}$ remains to be sold. From an economic standpoint this net amount of gas to be obtained is too small for the investment and exploitation of the installation, within this context. Therefore energy revenue is introduced and used within the EVA Centre. There is a (small) reduction of $\mathrm{CO}_{2}$ discharge and some energy saving. In the current configuration with CHP 
and composting of the sludge in the basement approximately $194 \mathrm{~kg} / \mathrm{home}$ *year of $\mathrm{CO}_{2}$ reduction for this district of 250 homes will be prevented (Sidler et al., 2004). To a certain extent there is also some reduction of waste collection and energy saving as a result of transport and pumping energy saved. When this saving is also taken into account, there is a total energy saving of approximately 8 GJ per home produced by the biogas installation $[8,9]$.

\section{Conclusions}

It is important to change the general attitude towards the different components of design, development, use and management of urban areas. A way to do so is the 'interconnection' of different themes and cycles within cities. An example is the linking of sanitation to energy- and food production, preferably at lower scale levels. Specific local circumstances are a strong stimulus for the implementation of whole life urban sustainability concepts based on decentralised systems for closing cycles on a local basis. Decentralised systems turn out to be able to gain efficiency advantages as compared to fully centralised systems, particularly through the design of an integrated system of energy generation and supply, and through the connection of this system to a waste and waste water treatment system coupled to nutrients and carbon recycling. In the presented case study, in which an anaerobic fermenter is used, the necessity of a protected environment for development was evident. The choices made arose mainly from technical and social optimisation. There are several reasons for the decreasing level of ambition for closing the local (waste) water flows in case of larger scales of application. Occupants turn out to have more commitment when systems perform on the scale of a house or apartment, as compared to the scales larger than a district. As scale size increases, the solutions get more and more anonymous and gives less possibilities for integration with its source/users (the buildings / houses), with decreasing commitment as a consequence.

The introduction of solutions on an intermediate scale-level, like in Lanxmeer, Culemborg, offers opportunities for autonomous design of the whole or elaborations in which buildings can be semi-autonomous. Introducing the analogy of the functioning of buildings with respect to energy and sanitation flows with that of a parasite ('waste equals energy' or: 'waste equals food') [10].

The example of the linking of agriculture, waste(water) treatment and energy production in the urban district Lanxmeer in Culemborg might be exemplary for the potentials of the supposed need for a change in attitude.

\section{References}

[1] Timmeren, A. van, Autonomie \& Heteronomie; Integratie en verduurzaming van essentiële stromen in de gebouwde omgeving. $\mathrm{PhD}$ Thesis, Delft University of Technology, Eburon Academical Publishers, Delft, The Netherlands, 2006 (English edition, November 2007).

[2] Timmeren, A. van, Kristinsson, J., Röling, L.C., The interrelationship of sustainability and resilience- \& vulnerability of networks, related to the 
critical flows in society; a future deadlock?. Proceedings International Conference Sustainable Building (SB05), Tokyo, Japan, 2005.

[3] Timmeren, A. van, Kristinsson, J., Röling, L.C., Existing infrastructures: a restriction for real sustainable development. In: The Sustainable City III. Urban Regeneration and Sustainability. Wessex Institute of Technology, WIT Press, Southampton, United Kingdom, 2004.

[4] Timmeren, A. van and Röling, L.C., Introducing Urban Agriculture concept in Urban Planning: The 'Park of the $21^{\text {st }}$ Century'. Proceedings Int. Conference Sustainable Building (SB05), Tokyo, Japan, 2005.

[5] Hasselaar, B.L.H., Graaf, P.A. de, Timmeren, A., van, Decentralised sanitation within the built environment casu quo integrated in living environments. In: The Architectural Annual 2005/2006, Delft University of Technology, Faculty of Architecture, Delft, The Netherlands, 2006.

[6] Kemp, R., Schot, J., Hoogma, R., Regime Shifts to Sustainability Through Processes of Niche Formation. The Approach of Strategic Niche Management. Technology Analysis \& Strategic management, Vol.10, No.2., 1998.

[7] Timmeren, A. van, Kristinsson, J., Röling, L.C., Sustainable Implant and EVA Centre, Culemborg; a hub for Sustainable Development. International Conference on Passive and Low Energy in Architecture (PLEA 2004), Eindhoven, The Netherlands, 2004.

[8] Sidler, H.F.A., Velsen, A.F.M. van, Gaalen, F. van, Bijman, Th., Lokale afvalverwerking met biogasproductie in Lanxmeer. CORE Int. Lochem, The Netherlands, 2004.

[9] Vries, G. de and Timmeren, A. van, Lokale afvalverwerking, lokale biogasproductie en lokale afvalwaterzuivering in de wijk EVA-Lanxmeer te Culemborg. BSE-2004, 2020-04-13-24-017, V\&L Consultants, Rotterdam / Atelier 2T -Architects, Haarlem, The Netherlands, 2006.

[10] McDonough, W., Braungart, M., Cradle to cradle. Remaking the way we make things. North Point Press, New York, USA, 2002.

[11] Todd J. \& Josephson, B. (1996) 'The design of living technologies for waste treatment, Ecological engineering, nr. 6. 